\title{
Determination of the Suitability of River Gurara Bed Sand Bonded with Clay for Foundry Casting Moulds
}

\author{
Nuhu A. Ademoh* Aminu Onimisi Ibrahim \\ Federal University of Technology, Minna, PMB 65, Minna, Nigeria
}

\begin{abstract}
The study investigated foundry properties of bed sand from river Gurara located in Niger State, Nigeria for use in production of foundry casting moulds using bentonite or kaolin clay as binders. A quantity of representative sand sample collected according to AFS procedure was washed, sun dried, classified on vibrated sieves and used for the experiment works. Specimens bonded with $0.5-3 \%$ of either bentonite or kaolin clay were prepared in accordance with AFS standard and tested for refractoriness; permeability; green/dry compressive strengths; moisture content; green hardness and shatter index using equipment including moisture teller, universal strength machine, shatter index and Rockwell hardness testers. The BS classification sieve result showed it consisted of $42 \%$ medium and $27 \%$ fine sand that will produce castings with fine surface finish. The physiochemical analyses done with XRF machine showed the sand was made up of $88 \%$ silica with metal/alkali oxides including $\mathrm{Fe}_{2} \mathrm{O}_{3}$ (3.02\%), $\mathrm{K}_{2} \mathrm{O}(3.02 \%), \mathrm{Al}_{2} \mathrm{O}_{3} \mathrm{TiO}_{2}(2.12 \%)$. It had refractoriness of $1,500^{\circ} \mathrm{C}$ making it suitable for casting moulds for non-ferrous metals, light/heavy grey iron and some grades of steel. Tested foundry properties including permeability (167-136No); green compressive $\left(26-38 \mathrm{KN} / \mathrm{m}^{2}\right)$, dry compressive strength (200$\left.360 \mathrm{KN} / \mathrm{m}^{2}\right)$; hardness (65-80); shatter index (88-70) for kaolin bonded specimen and (130-116); $\left(18-34 \mathrm{KN} / \mathrm{m}^{2}\right)$; $\left(182-238 \mathrm{KN} / \mathrm{m}^{2}\right)$; (48-54No); (110-76N0) for bentonite bonded specimen when compared with existing foundry standards also confirmed suitability of sand bonded with these clay for the applications mentioned.
\end{abstract}

Keywords: Gurara river, bed sand, Kaolin, Bentonite, Foundry

Keywords: Claims, Delivery, Administration

DOI: 10.7176/IEL/9-2-05

Publication date:March $31^{\text {st }} 2019$

\section{Introduction}

One of the ancient methods of metal forming is casting in foundry which involves such basic production processes as mould preparation, melting of metal, pouring into prepared mould, solidification, shake-out and fettling. The processes include permanent mould, centrifugal, die-casting, investment castings; sand and shell castings. Sand casting is the most widely used of the processes as it accounts for about $80 \%$ of cast product and can be employed for both ferrous and non-ferrous metals (Fatai et al, 2011). The study of foundry sand constitutes one of the main sections of foundry technology and sand tests have become essential parts of daily control of foundry operation. Property requirements of materials are determined by moulding and casting conditions (Fatai et al, 2011). Hence, proper choice of compositional moulding mixture is of prime importance. Foundry in Nigeria is still at infancy despite many decades of practice. Shuaib et al (2014) said that most foundries in Nigeria practice sand casting technique with $60 \%$ of needed raw materials imported and raised the need to domesticate the imports through intensive research and development efforts. This work was therefore designed to characterize river Gurara sand to assess its properties for possible application for foundry moulds. The main objectives are to characterize sand of river Gurara in Niger state, Nigeria for chemical, physical and mechanical properties to ascertain its suitability for casting mould applications. The results would be compared with past related studies in table 1 (Ademoh and Abdullahi, 2009) to determine level of suitability for validation based on the established standard sand properties in table 2 (Turkeli, 2009)

Table 1 Foundry Sand properties (Ademoh and Abdullahi, 2009)

\begin{tabular}{|c|l|c|c|c|}
\hline S/N & \multicolumn{1}{|c|}{ Metal } & Green Comp. Str $\left(\mathrm{KN} / \mathrm{m}^{2}\right)$ & Permeab (No) & Dry Stgth $\left(\mathrm{KN} / \mathrm{m}^{2}\right)$ \\
\hline $\mathbf{1}$ & Heavy Steel & $70-85$ & $130-300$ & $1000-2000$ \\
\hline $\mathbf{2}$ & Light Steel & $70-85$ & $125-200$ & $400-100$ \\
\hline $\mathbf{3}$ & Heavy Grey iron & $70-105$ & $70-120$ & $350-800$ \\
\hline $\mathbf{4}$ & Aluminium & $50-70$ & $10-30$ & $200-550$ \\
\hline $\mathbf{5}$ & Brass \& Bronze & $55-85$ & $15-40$ & $200-860$ \\
\hline $\mathbf{6}$ & Light Grey iron & $50-85$ & $20-50$ & $200-550$ \\
\hline $\mathbf{7}$ & Malleable iron & $45-55$ & $20-60$ & $210-550$ \\
\hline
\end{tabular}


Table 2 Particle size and sieve analysis (Turkeli, 2009)

\begin{tabular}{|c|l|l|}
\hline S/N & \multicolumn{1}{|c|}{ Sand Particle } & \multicolumn{1}{c|}{ Sizes } \\
\hline 1 & Soil separate & Diameter $(\mathrm{mm})$ \\
\hline 2 & Gravel & 2.0 and larger sizes \\
\hline 3 & Very coarse & $2.0-1.0$ \\
\hline 4 & Coarse & $1.0-0.5$ \\
\hline 5 & Medium & $0.5-0.25$ \\
\hline 6 & Fine sand & $0.25-0.10$ \\
\hline 7 & Very fine & $0.10-0.05$ \\
\hline 8 & Fines & Less than 0.05 \\
\hline
\end{tabular}

The significance of the study would that foundries in Niger and neighboring States will be availed with adequate information about usability of river Gurara bed sand as a close resources they can exploit for better production economics. This will help the industry grow by making it attractive to new investors.

\section{Materials and Methods}

The research experimental work were broken down and conducted in stages as enumerated below.

\subsection{Research Materials}

The main experimental materials for this work include but not limited to Gurara river bed sand, kaolin clay, bentonite clay, water, calcium carbide and assorted chemicals purchased from renowned chemical dealers. Sand samples were taken from five different points of about $100 \mathrm{~m}$ distance spread in between. At each point a depth of about $0.35 \mathrm{~m}$ was dug thrice and sand after every $0.35 \mathrm{~m}$ was excavated making 15 different samples. The 15 samples were mixed together to ensure true representation of river Gurara bed sand. The equipment used included moisture tester, universal sand strength machine, shatter index tester, British standard sieve pack, permeability tester and refractoriness testing kit. The experimental works were carried out at the National Metallurgical Development Centre, Jos in Plateau State.

\subsection{Research experimental methods}

The foundry property evaluation tests conducted on the sand samples included; sieve analysis, moisture content determination, permeability test, refractoriness test, dry and green compression strength tests, chemical analysis and shatter index. Experimental samples for this study were prepared based on the American Foundry Society (AFS) standard. Accordingly samples were dimensioned as $5.08 \mathrm{~cm}$ diameter by $5.08 \mathrm{~cm}$ height. Each of the following tests was sequentially conducted using standard procedures.

2.2.1 Chemical analysis

ED-XRFS did non-destructive test of quantitative and qualitative elemental analysis of solid and liquid sample materials. $20 \mathrm{~g}$ of sand sample was grounded to pass through $200-250$ mesh sieves. It was dried in oven at $105^{\circ} \mathrm{C}$ for an hour. Sample was mixed with binder (cellulose flakes) in ratio of 5:1 and was pelletized at a pressure of 10-15 tons/inch ${ }^{2}$ in the pelletizing machine. Thereafter the sample was kept in desiccators for analysis with the ED-XRFS switched on and allowed to warm up for about 2 hours. Appropriate programs for various elements of interest were employed to analyze the sample materials for their presence or absence. Results obtained were tabulated accordingly.

2.2.2 Sieve Analysis

AFS sieve analysis of sand was carried out to determine grain fineness on a dry sand sample from which all clay substance had been removed. A set of standard test sieve was used to screen sand as adopted by Ademoh (2008). Sieves were stacked in sequence with coarsest sieve on top and placed on sieve shaker. $150 \mathrm{~g}$ sand was placed on top sieve and after 15 minutes of vibration, weight of retained sand on a sieve was obtained. AFS grain fineness number was obtained by taking percentage retained sand on screen and multiplying each by a multiplier to arrive at product. Total sum of product added/divided by total sum of percentage retained sand on sieves gives AFS grain fineness number

$$
\text { AFS grain number }=\frac{\text { Total product }}{\text { Percentage of sand retained }}
$$

\subsubsection{Moisture content determination}

$6 \mathrm{~g}$ sand was weighed and transferred into moisture content tester. Two spoon full of granulated calcium carbide was quickly added to sand in tester and vigorously shaken for 2 minutes and reading from dial gauge indicating percentage moisture content was recorded. This procedure was repeated for samples with varying percentages of kaolin and bentonite content.

2.2.4 Permeability test

Permeability measured ease of escape of evolved gases to forestall defects like porosity and gas inclusions in 
casting. It depended upon grain size, grain shape, grain distribution, binder and content. AFS standard sand specimen of $50 \mathrm{~mm}$ diameter and $50 \mathrm{~mm}$ in height was prepared by ramming the required quantity of sand $(150 \mathrm{~g})$ in a smooth surface tube with three blows of standard rammer. Sample was placed in the mercury cup of permeability meter in an inverted form. The machine was switched on and the pressure lever was pushed. Readings were recorded when the arrow indicator was stable and represent the permeability number. Small orifices that were ten times less than the big orifices were used for this work. The procedure was repeated for test samples with varying percentages of kaolin and bentonite clay binders. Samples for permeability test measured $50 \mathrm{~mm}$ in diameter by $50 \mathrm{~mm}$ height. A ramming weight of $6.5 \mathrm{Kg}$ delivered in 3 blows was used in accordance with AFS.

\subsubsection{Refractoriness test}

It measured fusion point and thermal stability of sand to tell the type of alloy it is suitable for casting (Ademoh, 2008). Cuboids sand specimens measuring 10.8 X 5.3 X 2.0cm were prepared with binder and pressed at 300pa, heated to $1200^{\circ} \mathrm{C}$ and then gradually increased to $1700^{\circ} \mathrm{C}$ for 2 hours with changes in dimension and appearance observed. Initially specimen shape showed little expansion but began to shrink and distort at $1,500^{\circ} \mathrm{C}$ and refractoriness of $1,500^{\circ} \mathrm{C}$ recorded.

\subsubsection{Dry compression strength}

This property indicated strength of sand mould in dry condition in deformation showing its ability to withstand pressure of molten metal in casting. Samples were prepared with standard sand rammer and specimen tube accessories. Sand and clay were thoroughly mixed in a roller for 10 minutes and moulded into specimens that measured $50 \mathrm{~mm}$ diameter by $50 \mathrm{~mm}$ height and averagely weighed $130 \mathrm{~g}$. It was rammed with three dropping blows weighing $6.5 \mathrm{~kg}$ from $50 \mathrm{~mm}$ height. The first scheduled test sample was bonded with only water, second bonded with varying percentages of bentonite and the third with varying percentages of kaolin clay. AFS standard sample $\left(50 \mathrm{~mm}\right.$ diameter x $50 \mathrm{~mm}$ height) was heated and oven dried at standard temperature of $110^{\circ} \mathrm{C}$ for a period of 30minutes, removed and allowed to cool in air to room temperature. After cooling, specimens were placed between two self aligning compressions; increasing load was applied until it failed at the ultimate compression strength of sample. The point at which failure occurred was recorded as dry compressive strength. The same procedure was repeated for samples with varying percentages of bentonite and kaolin as binder.

\subsubsection{Green Compression Test}

It determined strength of mould in moist condition at deformation. Strength depended on degree of ramming, moisture and granulation composition of sand. Specimen was prepared using standard sand rammer and specimen tube accessories to specifications $50 \mathrm{~mm} \times 50 \mathrm{~mm}$. Each was placed in between two self aligning compression heads in the universal tester. A uniformly increasing load was applied while the magnetic rider moved along a measuring scale. As soon as sample reached its maximum strength, it failed. The magnetic rider remained in position of the ultimate strength while load was gradually released. The GCS for sample was recorded from the position of the magnet. The procedure was repeated for samples with varying percentages of bentonite and kaolin binders.

\subsubsection{Hardness Test}

This measured mould resistance against abrasion to ensure casting accuracy. The hardness achieved by ramming sand mixture was measured by using an indentation-type hardness tester where a spring-loaded 1/2 inch diameter steel ball was pressed into AFS standard sample with hardness number read directly from dial gauge calibrated from 100 to 0 in idle mode with reading arbitrarily set to 100 . Where the ball sunk completely into sand up to the limiting surface of tester, the reading was set to 0 ; i.e. sand was very soft. "Hard rammed" mould generally read 90, while "soft" mould read 50 to 60 . Severe penetration by liquid metal and washing of the sand occurred if hardness reading was below 50. Same procedures were repeated for samples with varying percentage of bentonite and kaolin as binder.

\subsubsection{Shatter index test}

The shatter index test was carried out using shatter index tester at NMDC Jos. The standard specimen of size $50 \mathrm{~mm}$ diameter and $50 \mathrm{~mm}$ height was prepared and kept in the steel tube as in case of permeability. The tube holding the specimen was fixed on the machine. The plan (receiver) was set at zero and fixed on the normal position at the foot of the machine directly below the specimen. The handle of the mechanism was pulled downward, the plunger entered and ejected the specimen from the steel tube. The sand fell under gravity and hit the anvil in the sieve on top of the receiver. The mass of the sand in the receiver was measured and the shatter index was calculated for each mix as follows, Initial mass of the sand, M0; Mass of sand in the Receiver, M1

$$
\text { Shatter index }=\frac{M 0-M 1}{M 0} \times 100
$$

The same procedure was repeated with varying percentages of bentonite and kaolin used as binders. 


\section{Results and Discussions}

The results of the experimental works are as presented and discussed accordingly.

\subsection{Chemical analysis}

Chemical analysis determined silica content, aluminum oxide and other impurities in sand. In table 3 are the compositions determined with XRF showing amounts of silica and impurities like lime, manganesia, alkalis etc. Excess iron oxide (3.02\%), alkali oxides $\mathrm{K}_{2} \mathrm{O}(3.02 \%), \mathrm{Al}_{2} \mathrm{O}_{3}$ and $\mathrm{TiO}_{2}(2.12 \%$.each) and lime are usually undesirable in foundry sand as they largely lower fusion point (Turkeli, 2009).

Table 3: Chemical analysis of river Gurara bed sand at Niger state

\begin{tabular}{|l|l|l|}
\hline S/NO & Component Element & Composition by weight (\%) \\
\hline 1 & $\mathrm{SiO}_{2}$ & 88.80 \\
\hline 2 & $\mathrm{Al}_{2} \mathrm{O}_{3}$ & 2.12 \\
\hline 3 & $\mathrm{SO}_{3}$ & $\mathrm{ND}$ \\
\hline 4 & $\mathrm{~K}_{2} \mathrm{O}$ & 3.02 \\
\hline 5 & $\mathrm{CaO}$ & 0.50 \\
\hline 6 & $\mathrm{TiO}_{2}$ & 2.12 \\
\hline 7 & $\mathrm{~V}_{2} \mathrm{O}_{5}$ & 0.06 \\
\hline 8 & $\mathrm{Cr}_{2} \mathrm{O}_{3}$ & 0.11 \\
\hline 9 & $\mathrm{MnO}_{2}$ & 0.06 \\
\hline 10 & $\mathrm{Fe}_{2} \mathrm{O}_{3}$ & 3.02 \\
\hline 11 & $\mathrm{NiO}_{2}$ & 0.005 \\
\hline 12 & $\mathrm{CuO}$ & 0.01 \\
\hline 13 & $\mathrm{ZnO}$ & $\mathrm{ND}$ \\
\hline 14 & $\mathrm{As} \mathrm{O}_{3}$ & 0.004 \\
\hline 15 & $\mathrm{Rb} \mathrm{O}_{2}$ & 0.009 \\
\hline 16 & $\mathrm{SrO}$ & 0.02 \\
\hline 17 & $\mathrm{ZrO}$ & 0.33 \\
\hline 18 & $\mathrm{PbO}$ & 0.02 \\
\hline 19 & $\mathrm{Loss}$ on Ignition & 1.13 \\
\hline
\end{tabular}

However, high presence of Silica $\left(\mathrm{SiO}_{2}\right)$ of up to $88.80 \%$ in line with recommended basic sand molding constituents countered negative effect of iron and alkali oxide in sand on refractoriness (Turkeli, 2009). Other constituents like manganese, calcium, chromium oxides with others are in negligible proportions and made no significant reduction tendency in refractoriness of sand enabling it retain high fusion point of $1,500^{\circ} \mathrm{C}$. Based on the result the sand is chemically suitable for ferrous and non-ferrous castings as no contaminating compounds were found in undesirable proportion.

\subsection{Refractoriness}

Refractoriness was found to be $1,500^{\circ} \mathrm{C}$. It gave very useful information about the thermal resistance of Gurara river bed sand showing that is suitable for production of casting moulds for selected types of non ferrous and ferrous alloy metals as observed by Ademoh (2008) on river Niger bed sand that exhibited refractoriness of $1,380^{\circ} \mathrm{C}$ and adjudged suitable for casting non ferrous alloys with melting points below $1,380^{\circ} \mathrm{C}$. The sand is also suitable for selected ferrous alloys that melt below $1,500^{\circ} \mathrm{C}$.

\subsection{Sieve analysis}

The grain distribution of sand is as presented table 4 . 
Table 4: Mechanical Sieve analysis of sand sample

\begin{tabular}{|l|l|l|l|l|l|l|}
\hline S/N & Sieve size (mm) & Weight Retained (g) & $\mathbf{( \% )}$ Retained & $(\mathbf{\%})$ Cumulative & Multiplier & Product \\
\hline $\mathbf{1}$ & 1.40 & 7.85 & 5.23 & 5.23 & 6 & 31.38 \\
\hline $\mathbf{2}$ & 1.00 & 13.01 & 8.669 & 13.899 & 9 & 78.021 \\
\hline $\mathbf{3}$ & 0.71 & 32.11 & 21.39 & 35.289 & 15 & 320.85 \\
\hline $\mathbf{4}$ & 0.50 & 32.92 & 21.93 & 57.219 & 25 & 548.25 \\
\hline $\mathbf{5}$ & 0.355 & 26.75 & 17.82 & 75.039 & 35 & 623.7 \\
\hline $\mathbf{6}$ & 0.250 & 17.84 & 11.88 & 86.919 & 45 & 534.6 \\
\hline $\mathbf{7}$ & 0.18 & 9.39 & 6.257 & 93.176 & 60 & 375.42 \\
\hline $\mathbf{8}$ & 0.125 & 7.45 & 4.96 & 98.136 & 81 & 401.76 \\
\hline $\mathbf{9}$ & 0.09 & 1.192 & 1.279 & 99.415 & 118 & 150.922 \\
\hline $\mathbf{1 0}$ & 0.063 & 0.65 & 0.433 & 99.848 & 164 & 71.012 \\
\hline $\mathbf{1 1}$ & Pan/Clay & 0.17 & 0.113 & 99.96 & 275 & 31.075 \\
\hline & Total & $\mathbf{1 5 0 . 0 6}$ & $\mathbf{9 9 . 9 6}$ & & & $\mathbf{3 1 6 6 . 9 9}$ \\
\hline
\end{tabular}

The AFS fineness number, the standard for reporting grain size and distribution was used to assess the particulate distributions as done by Ademoh (2008). From table 4 and equation 2, AFS fineness number was computed to be 31.68. Sand grain size and distribution greatly affected its property as it determined likely surface finish of casting. Size/shape of silica sand grain had large bearing on strength and other general characteristics. Sand with wide range of particle sizes had higher compatibility than that with narrow distribution (Turkeli, 2009). The sieve analysis showed it as more of medium, fine and very fine sand because $70 \%$ of its size falls within $0.18 \mathrm{~mm}-0.75 \mathrm{~mm}$ on sieve. Specifically, $42 \%$ sand was within medium and $27 \%$ was fine sand confirming therefore that it will give a good surface finish to a casting.

\subsection{Mechanical Properties}

The most tested of all mechanical properties of moulding sand are permeability, green compression, dry compression, hardness and shatter index. Table 5 shows the result of foundry property tests of moulded sand specimens bonded with water only while figures 1,2, 3 and 4 present measured foundry properties of the bed sand bonded with 3\% moisture and various percentages of bentonite and kaolin respectively.

Table 5: Mechanical foundry properties of River Gurara Bed Sand with varied percentage water

\begin{tabular}{|l|l|l|l|l|l|l|l|}
\hline \multirow{2}{*}{$\mathbf{S} / \mathbf{N}$} & \multirow{2}{*}{ Measured properties } & \multicolumn{4}{l}{ Varied water content (\%) } \\
\cline { 3 - 8 } & & 2.0 & 3.0 & 4.0 & 5.5 & 7.0 & 8.0 \\
\hline $\mathbf{1}$ & Permeability & 12.2 & 10.4 & 9.6 & 8.1 & 7.8 & 6.2 \\
\hline $\mathbf{2}$ & Green Compression Strength $\left(\mathrm{KN} / \mathrm{m}^{2}\right)$ & NA & NA & NA & NA & NA & NA \\
\hline $\mathbf{3}$ & Dry Compression Strength $\left(\mathrm{KN} / \mathrm{m}^{2}\right)$ & NA & NA & NA & NA & NA & NA \\
\hline $\mathbf{4}$ & Green Hardness (No) & NA & NA & NA & NA & NA & NA \\
\hline $\mathbf{5}$ & Shatter Index (No) & 11.6 & 10.6 & 7.8 & 5.4 & 3.2 & 1.4 \\
\hline
\end{tabular}

In table 5 result of mechanical properties it was observed that when bed sand was bonded with different amounts of water only, permeability was far below the recommended value for foundry and as such not suitable for casting (Ademoh and Abdullahi, 2009). The green compression/dry compression strengths and green hardness gave no readable result as the sand bonded with only water was too weak. Its shatters index result was far below acceptable standard and therefore concluded that water only would not impart reasonable properties on the sand for casting as its residual clay was not sufficient. Figure 1 presents the result of permeability, green/dry compressive strength, green hardness and shatter index of specimens bonded with $0.5 \%, 1.0 \%, 1.5 \%, 2.0 \%$, $2.5 \%$ and $3.0 \%$ bentonite clay. 


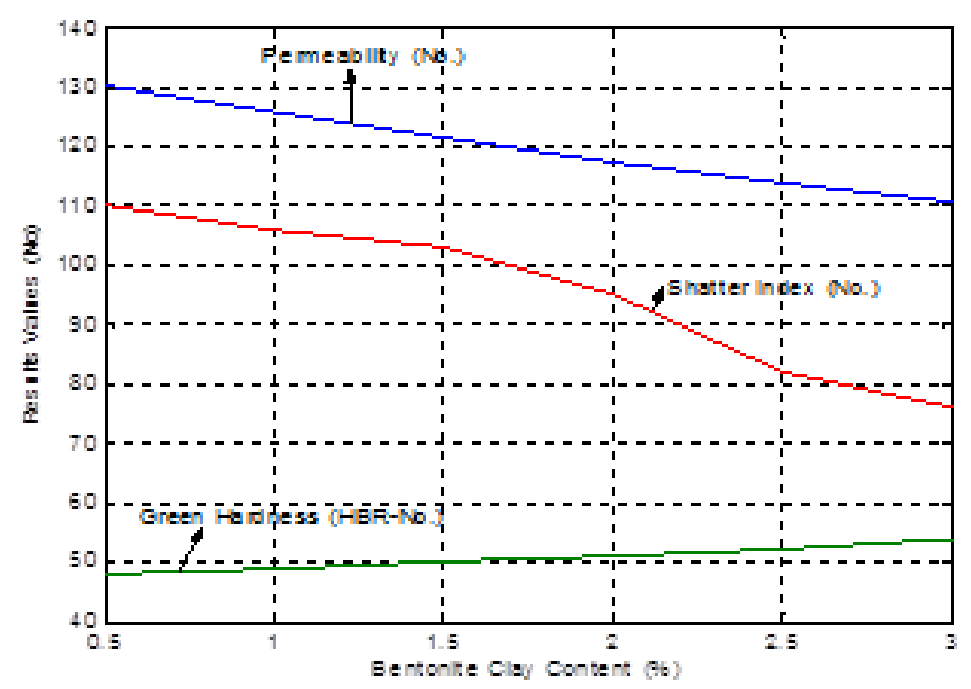

Figure 1:- Permeability (No.); Shatter Index (No.) and Green Hardness (HRB-No.) against increased Bentonite Clay Binder Content.

In the result, permeability decreased as clay increased from $0.5 \%-3 \%$ and more clay particles filled up free spaces to lower air passage. Its comparison with foundry standard (table 1 ) showed $0.5 \%$ bentonite bonded sand was suitable for heavy, $1.0 \%$ for light steel and $2.0 \%-3.0 \%$ for heavy grey iron casting. Green/dry compression strength and hardness increased with increased clay. The trend occurred because increased clay caused increased binding strength as more available reactions between clay sand grains raised bond energy. Figure 2 gives green/dry compressive strength of sand bonded with bentonite clay.

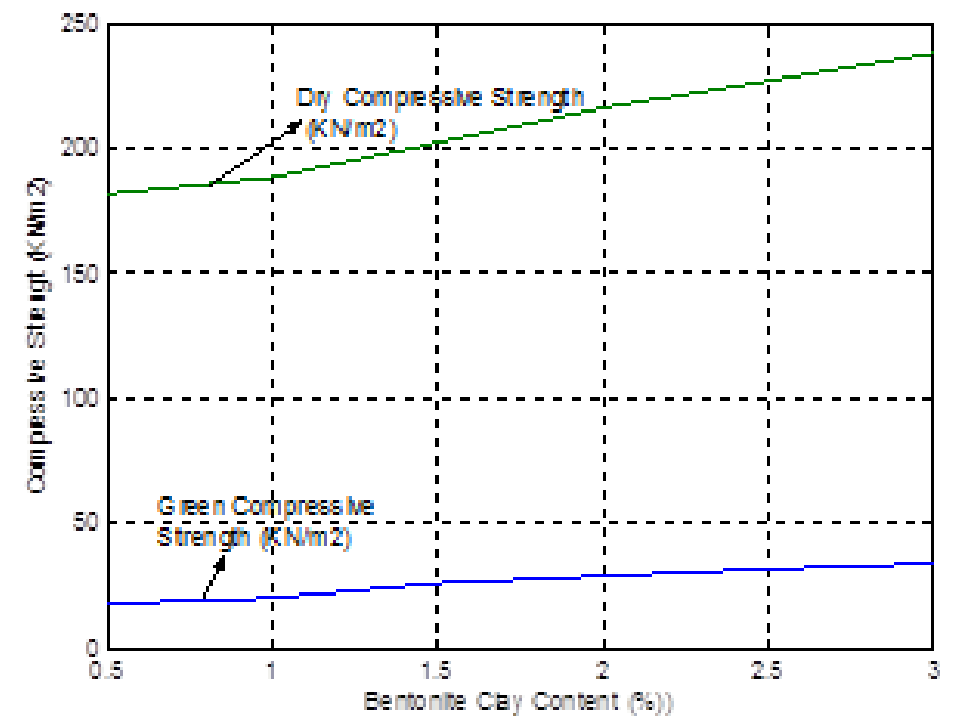

Figure 2:-Green and Dry Compressive Strengths $\left(\mathrm{KN} / \mathrm{m}^{2}\right)$ against increased Bentonite Clay Content

In the figure, green and dry compressive strength increased steadily with increased bentonite clay binder showing the sand is adequately mouldable for foundry use with binder and sufficient moisture presence. When compared with foundry standard it showed that bentonite is unsuitable for green mould casting but good for dry mould casting of non-ferrous alloys, malleable and light grey iron from $2.0 \%$ to $3.0 \%$. Shatter index decreased with increased binder from 110- 76.0 due to increased compactness as adduced. In figure 3, the result of permeability, green/dry compression strength, green hardness and shatter index tests of sand sample bonded with $0.5 \%, 1.0 \%, 1.5 \%, 2.0 \%, 2.5 \%, 3.0 \%$ kaolin clay and $3 \%$ added water. 


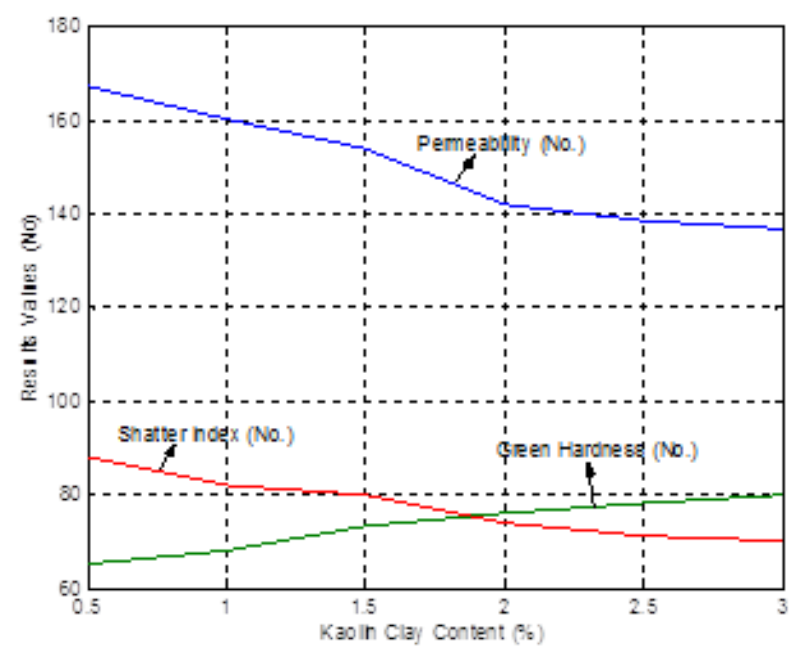

Figure 3:-Permeability (No.); Shatter Index (No.) and Green Hardness (HRB-) against increased Kaolin.

Permeability decreased as clay content increased from $0.5 \%$ to $3 \%$ because more clay particles filled up available free spaces and reacted with moisture around sand grains to form close packed mass of mould thereby lowering air passage. The result further confirmed that river Gurara bed sand is only suitable for foundry uses when binder is added with moisture to form synthetic mould sand as it cannot function properly with only water unlike natural sands accompanied with binding agents. When compared with established foundry standard it showed $0.5 \%-3.0 \%$ kaolin bonded moulds are suitable for heavy and light steel casting. Green/dry compression strength and hardness increased with increased bond clay. In figure 4 are results of green and dry compressive strengths of sand moulded with kaolin clay and water.

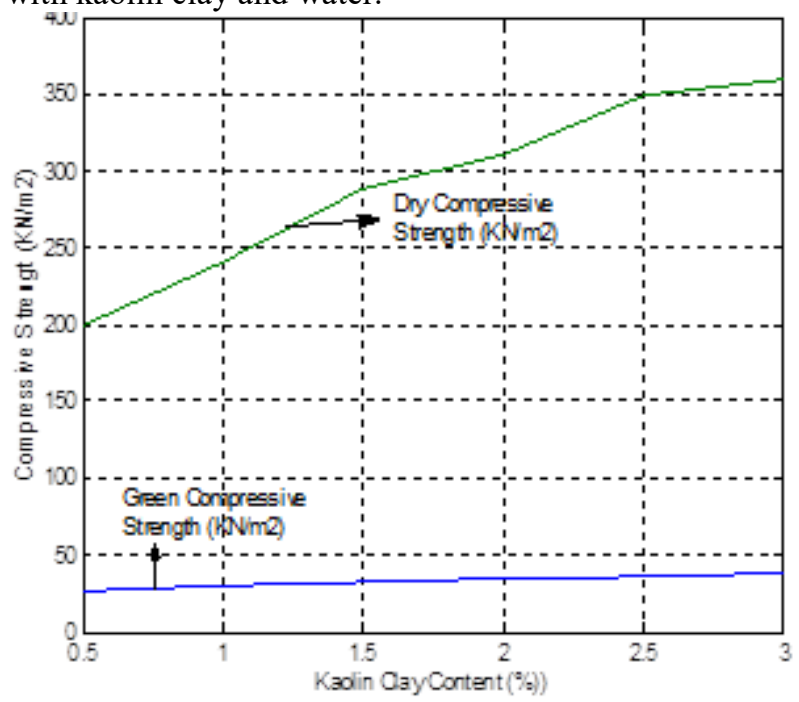

Figure 4:- Green and Dry Compressive Strengths $\left(\mathrm{KN} / \mathrm{m}^{2}\right)$ against increased Kaolin clay content

The observed increase in strength occurred because as clay content of sand increased, binding strength also increased due to more reactions between sand and clay particles resulting to stronger inter-particulate bonds that increased strength and hardness. The green/dry compressive strength when compared with established foundry standard in table 1, it showed that kaolin within the compositional content range was unsuitable for green mould casting but suitable for dry mould casting of non-ferrous alloys, malleable and light grey iron from $2.0 \%$ to $3.0 \%$. $3.0 \%$ clay bonded sand is suitable for heavy grey iron and medium grey iron. Shatter index number decreased with increased binder content from 88.0 to 70.0 due to increase in compactness as a result of the increased binder as explained above.

3.5 Cross comparison of mechanical property of bentonite versus kaolin clay bonded sand moulds Figure 5 shows combined graphical plots of results of permeability, green hardness and shatter index of mould specimens bonded with either bentonite clay or kaolin clay for intra comparison of performance. 


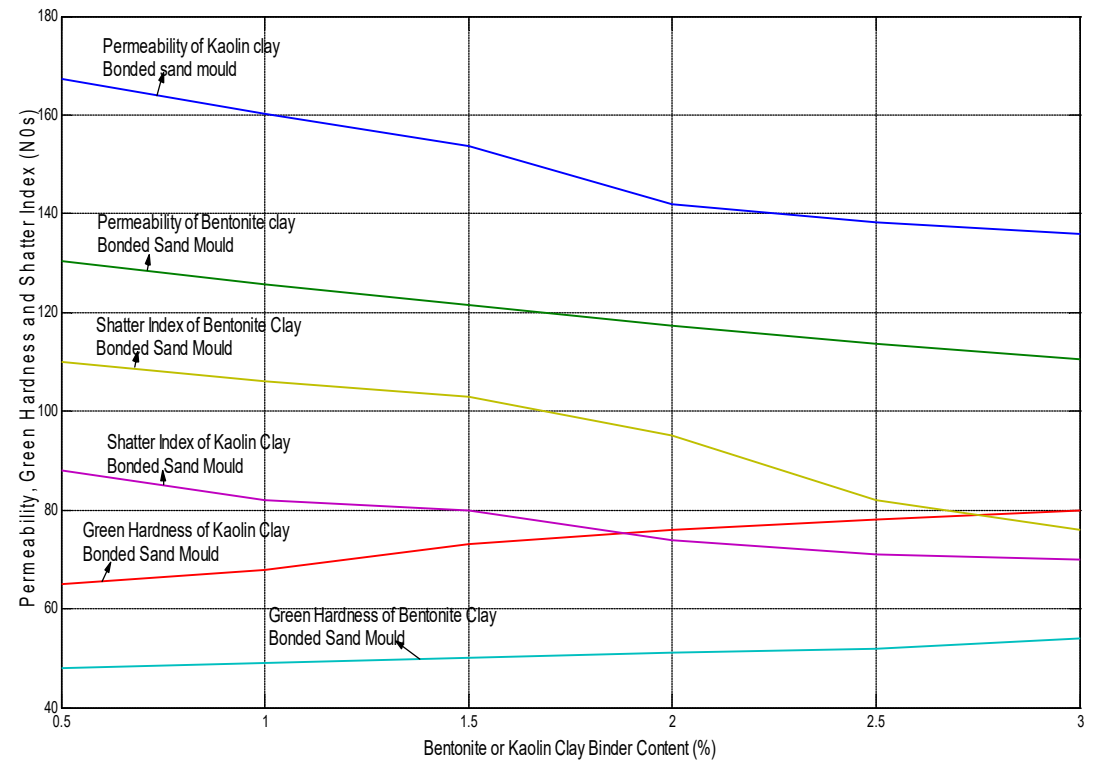

Figure 5:-Permeability; shatter index (No) and green hardness (HRB) versus bentonite/kaolin contents.

It is obvious from the results that kaolin bonded sand had higher permeability implying less internal pressure build up with lower related defect than bentonite bonded sand. Higher green hardness of kaolin bonded sand; a feature collaborated by its lower shatter index showed its moulds had higher resistance to damage and therefore more suitable than moulds of bentonite bonded sand. Figure 6 shows combined plots of green/dry compressive strength for bentonite and kaolin clay bonded sand mould specimens for comparison of the performance of each binder when used separately.

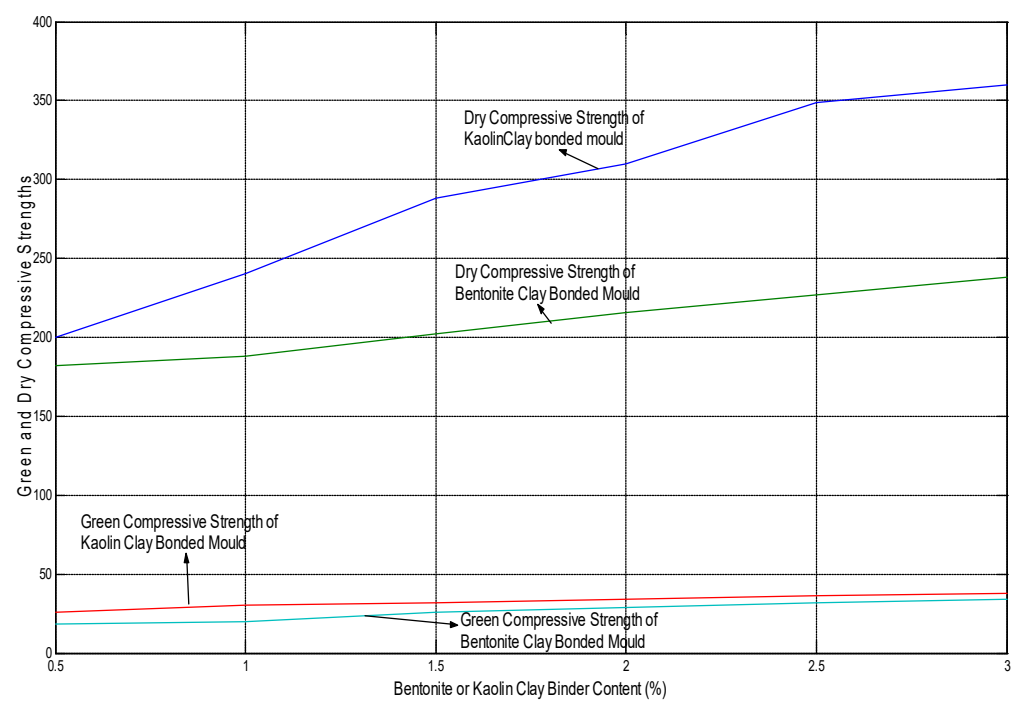

Figure 6:- Green and dry compressive strengths $\left(\mathrm{KN} / \mathrm{m}^{2}\right)$ versus Bentonite or Kaolin clay content

In the result, the trend observed in figure 5 was also evident here as both the green and dry compressive strengths of kaolin clay bonded sand specimens were higher than those of bentonite clay bonded moulds asserting the superiority in stronger bond formation. This makes the clay more acceptable for the Gurara river bed sand in heavy ferrous and non ferrous casting moulds that require high strength and reasonable permeability to prevent sand control related casting defects like scabs, inclusions and surface roughness.

\section{Conclusion}

The study revealed through physiochemical property tests that river Gurara bed sand had high silica content that imparted high refractoriness to it. This made it suitable for casting many non-ferrous metals and selected classes of ferrous metal that melt below $1,500^{\circ} \mathrm{C}$. The sand responded well to bentonite and kaolin clay binders to impart good mechanical properties on sand mould. Mechanical properties moulds made with the sand compared favourably with established foundry standards as moulds bonded with the two clay binders were found very suitable for casting most types of non-ferrous and some classes of ferrous alloy like heavy/light steel casting 
$(0.1-3 \%)$; heavy grey iron $(2.0 \%-3.0 \%)$ bentonite bonded with $2 \%$ moisture. Sand mould bonded with kaolin clay contents of $2.0 \%-3.0 \%$ and that of $3.0 \%$ clay with $2 \%$ moisture were suitable for malleable/light and heavy iron/medium grey iron respectively and non-ferrous castings. Since the scope of this work was to determine suitability of river Gurara bed sand for production of casting mould it is recommended that is its suitability for cores for different types of casting be investigated in future studies. Conclusively, kaolin clay was observed to be a better binder for the sand for most applications than bentonite clay. This is good as kaolin is also much more available.

\section{References}

Ademoh, N.A (2008). Evaluation of the Foundry Properties of River Niger Sand Behind Ajaokuta Steel Company Ltd, Ajaokuta, Nigeria. American-Eurasian Journal of Scientific Research, 3(1), 75-83.

Ademoh, N.A (2009). Evaluation of Mechanical Properties of Expandable Foundry SandCores Bonded with Composites Made of Kaolin Clay and Grades 1 and 4 Gum Arabic. American-Eurasian Journal of Scientific Research, 4(3), 117-123.

Ademoh, N.A (2010). Evaluation of Mechanical Properties of Expandable Foundry Sand Cores Bonded with Composites Made of Kaolin Clay and Grades 1 and 4 Gum Arabic. International Journal of the Physical Sciences, 5(5), 557-563.

Ademoh N. A and Abdullahi A. T (2009). Assessment of Foundry Properties of Steel Casting Sand moulds Bonded with the Grade 4 Nigerian Accicia Species (Gum Arabic). International Journal of the Physical Sciences, 4(4), 238-241.

Fatai, O.A., Sunday, A. \& Davies, O.F. (2011). Optimizing the Moulding Properties of Recycled Ilaro Silica Sand, Leonardo Journal of Sciences, 93-102

Murtala, A.G (2009). Assesment of the moulding properties of River Niger Bank Sand Around Jebba: For Use in Foundry: Unpublished MSc. Thesis, Department of Mechanical Engineering, Bayero University Kano.

Shuaib-Babata, Y.L and Olumodeji. J.O. (2014). Analysis of Ilorin Sand Moulding Properties for Foundry Applications, International Journal of Engineering Research \& Technology (IJERT) Vol. 3 Issue 1, January $-2014$

Turkeli, A. (2009). Foundry technology. London, Macmillan press publishers, Pg 432 